DOI: http://dx.doi.org/10.33846/hn41004

http://heanoti.com/index.php/hn

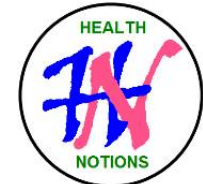

RESEARCH ARTICLE

URL of this article: http://heanoti.com/index.php/hn/article/view/hn41004

\title{
Self-Care Behavior in Diabetes Mellitus Patients Using Herbals as a Complement to Treatment
}

\author{
Anita Joeliantina $^{1(\mathrm{CA})}$, Hepta Nur Anugrahini ${ }^{1}$ \\ ${ }^{1(\mathrm{CA})}$ Department of Nursing, Poltekkes Kemenkes Surabaya, Indonesia; anita@poltekkesdepkes-sby.ac.id \\ (Corresponding Author) \\ ${ }^{2}$ Department of Nursing, Poltekkes Kemenkes Surabaya, Indonesia
}

\begin{abstract}
Diabetes mellitus (DM) is a chronic disease that requires treatment or management in the long term. DM patients have a tendency to seek other treatment besides medical treatment. The use of herbs is one of the choices for DM patients in complementing self-care, especially in the treatment component. This study aims to explore in depth about self-care behavior in DM patients who use herbs as a complement to medical treatment. This study used a qualitative design with a phenomenological method approach. Participants were determined by purposive sampling technique as many as 9 participants. Data collection was carried out in August and October 2015 with in-depth interview techniques. Data analysis using Interpretative Phenomenological Analysis. The data validation was done by using triangulation technique. There are three themes generated in this study, namely: 1) reasons for going to health services, 2) patient expectations after being diagnosed with diabetes, and 3) diabetes self-care. DM patients who have a tendency to use herbs as a complement to medical treatment must continue to carry out self-care regularly so that their blood sugar levels are controlled. The pattern of diabetes self-care behavior needs the attention of health workers, so that DM patients continue to carry out self-care regularly when using herbs as a companion to medical treatment.
\end{abstract}

Keywords: diabetes mellitus; herbs; self-care

\section{INTRODUCTION}

Diabetes mellitus (DM) is a group of metabolic diseases characterized by hyperglycemia that occurs due to abnormalities in insulin secretion, insulin action, or both. This disease, if not managed properly, can lead to acute complications and reduce the risk of long-term complications ${ }^{(1,2)}$.

The prevalence of DM patients in Indonesia ranks seventh in the world along with China, India, the United States, Brazil and Mexico with an estimated number of people with diabetes of 10 million in 2015 and will increase to 16.2 million by 2040. The percentage of deaths Patients due to DM in Indonesia are the second highest after Sri Lanka ${ }^{(3)}$. In Indonesia, the number of DM sufferers obtained based on interviews also increased from 5.9 percent in 2013 to 8.5 percent in $2018^{(4)}$.

$\mathrm{DM}$ is a chronic disease that will last a lifetime. A person who has a chronic illness always finds it difficult to accept the fact that they have to change their lifestyle. They have to adhere to and adapt to new, different routines, such as getting insulin shots, eating healthy foods and doing physical exercise. Patients must be able to integrate DM pressure into daily routines ${ }^{(5)}$.

Chronic illness creates feelings of loss, such as increasing financial hardship for most individuals and bringing about changes in lifestyle and dependence on others ${ }^{(6)}$. The psychological response shown by DM patients is feelings of fear, anxiety, confusion, rejection, and someone who can accept the disease ${ }^{(7)}$. This response can affect the self-care behavior of DM patients. Diabetes self-care behavior consists of diet regulation, activity, independent monitoring of blood sugar levels, medication adherence, behavior to reduce the risk of complications, and problem solving ${ }^{(8,9,10)}$.

DM treatment must be carried out for life. The treatment used by DM patients is not only conventional medicine, but there are patients who use complementary and alternative medicine (CAM). 85\% T2DM patients to use herbs or medical platns in an effort to improve their health status. Herbs that are widely used by T2DM patients include: bay leafs, cinnamon, fenugreek, black seed, garlic, and momordica charantia. Sixty-nine percent of the patients were satisfied with using herbs as complementary and traditional treatments ${ }^{(6,11,12)}$. T2DM patients, apparently still have inappropriate self-care behavior when using herbs and patients tend not to comply with medical treatment ${ }^{(13)}$. Patients also have the habit of using more than one herbal at the same time ${ }^{(12,14)}$. This becomes the basis for conducting research on self-care for DM patients using herbs. 
This study aims to explore in depth about the self-care behavior of DM patients using herbs in the outpatient department of traditional Indonesian medicine at the dr. Sutomo General Hospital, Surabaya.

\section{METHODS}

This study used a qualitative design with a phenomenological method approach, focusing on DM patients who used complementary medicine. Nine participants were selected based on a purposive sampling technique. The criteria for the participants were using herbs as a complement to medical treatment for at least 3 months, suffering from diabetes for more than one year, and the patient's age ranged from 30-65 years. Participants are patients who are or have visited the outpatient department of traditional Indonesian medicine at the dr. Sutomo General Hospital, Surabaya.

Data collection was carried out in August and October 2015, with each participant's home visit. Data collection techniques used in-depth interviews and field notes to explore patient perceptions in carrying out self-care. All participants have an initial explanation of the study, procedures and participant rights, and sign an informed consent. Interviews were conducted by researchers for 30-60 minutes and all processes were recorded using a voice recorder.

Methods of data analysis using Interpretative Phenomenology Analysis. The stages of Interpretative Phenomenology Analysis are as follows: 1) Reading and rereading; 2) Initial recording (recording all transcripts); 3) Developing emerging themes; 4) Looking for relationships between emerging themes; 5) Transferring the next case (moving on to the next case or participant until all cases are completed); and 6) Look for patterns across cases (look for patterns that emerge between cases / participants).

The data validation used communicative and descriptive validity to the participants to confirm the data that had been obtained. Validation is carried out by observing the participant's living environment and triangulation techniques through family members of the participants (husband or wife or children).

This study has received ethical approval through an ethical test by the ethics committee of the the dr. Sutomo General Hospital, Surabaya with Number 449 / Panke. KKE / IX / 2015.

\section{RESULTS}

The number of participants in this study was 9 people, 3 people were being treated at the outpatient department of traditional Indonesian medicine at the dr. Sutomo General Hospital, Surabaya and the remaining 6 people had experience in taking medical care at the outpatient department of traditional Indonesian medicine in 2015. Data about DM patients obtained from the outpatient department of traditional Indonesian medicine were patients, who have participated in the herbal use program. The herbs used are in andrographis paniculata, Indonesian bay leaf, and breadfruit leaf which are packaged in single or combination capsules.

\section{Characteristics of participants}

All participants are women. The ages of the participants ranged from 45-65 years, with a distribution of 4 participants aged 45-50 years, 3 participants aged 51-55 years, and 2 participants aged 61-65 years. The participant education data is that one participant did not complete elementary school, 7 participants graduated from secondary school (or equivalent), and 1 participant was a Bachelor. All participants were diagnosed with type 2 diabetes mellitus by a doctor and had suffered from it for more than one year, with 6 people from 1-5 years and 3 to 6-10 years. While the period of using complementary medicine is more than 3 months, with the category 3-12 months as many as 4 people, 1-5 years as many as 4 people, and more than 5 years as many as 1 person.

\section{Themes}

The results of in-depth interviews with participants obtained three themes, namely: reasons for going to health services, expectations of patients after being diagnosed with DM, diabetes self-care.

\section{$\underline{\text { Reasons to go to health services }}$}

All participants stated that they knew they had DM disease from their doctor. Participants visited health facilities due to complaints. The following are statements of participants who are the reasons why they checked themselves into health facilities. Five participants stated that they visited the doctor because of several health complaints such as weakness, thinness, frequent urination, and drowsiness.

"I often feel my hands lighten and my body feels bad" (P1),

"My cholesterol is high, then I feel my body is getting thinner" (P3),

"I checked it because my body didn't feel good" (P6),

"I checked my hypertension, then checked my blood sugar level, it turned out that my fasting blood sugar level was high, namely 160" (P8),

"Ifeel that I have complaints that I am easily tired, my legs feel thick, I feel gnarled, my body is getting thinner" (P9) Expectations of patients after being diagnosed with DM

The following is a participant statement that shows the participants' psychological and physical expectations in controlling their disease

Psychological expectations: 
"The important thing is to be enthusiastic", "Just surrender to Allah", "don't stress, just surrender, I'm already old ...", resigning with free time is used for dhikr", "control yourself", hope to be healthy, let go by enjoying the disease, take care of yourself, don't have to think about things, hopefully there will be no complications. (P2, P5, P6, P7, P9)

Physical expectations:

"I can take care of eating", "be careful when eating", "adjust the diet, do not eat carelessly", exercise regularly", "must take medication for life", "drink regular medication", “controlled blood sugar levels". (P1, P3, P4, P8)

\section{Diabetes Self-care}

The resulting sub-themes were knowledge about self-care, regulating diet, regular exercise, independent monitoring of sugar levels, medication adherence, and foot care. The following is self-care carried out by participants.

Knowing the implementation of self-care

Seven participants knew about the implementation of self-care but could not implement it regularly.

"I know, because when I was in control I got the information, but I still can't do it", "sometimes I forget what was said", "doing it is still difficult", "I can't do it routinely". (P1, P2, P3, P4, P5, P6, P9)

Adjust the diet

The principle of eating arrangements in DM patients: almost the same as the recommended healthy eating in general, there are no prohibited foods, only limited calories (not excess), the diet is the same as the family menu, and must be on schedule, the right type and the right amount. Six participants stated that they could not manage to eat properly, as evidenced by the patient's statement as follows:

"Sometimes I get confused, like food, what to set up" (P1),

"Especially food is still haphazard, can't manage properly" (P3 P6 P7),

"When eating, I still like it carelessly, I still can't avoid foods such as salty, sweet, fatty foods, I still eat a lot” (P4),

"I don't have a regular diet" (P9)

Exercise regularly

Regular exercise is highly recommended in DM patients. Seven participants did not exercise regularly:

"I don't exercise regularly, because I am busy doing my chores at home" (P1, P9), because at home I have a business so I'm tired". (P2), "I rarely exercise", (P6), "Every day I sport riding a bicycle because I have to go around selling ice" (P7).

Compliance with taking medication

Adherence to taking medication in this study revealed the behavior of using herbs as a complement to medical treatment. Participants have experience using more than one herb to manage their disease. Following are statements from participants showing treatment adherence behavior.

"I took the drug metformin, as I remember it. I am currently drinking herbal (andrographis paniculata). I also consume bitter melon, I boil it and then I eat it". (P1)

"I took medicine from a doctor. I often consume Indonesian bay leaves, cymbopogon citratus, ginger, noni, Phyllanthus urinaria, alternately at least 2 times a week for almost 2 years". (P3)

"I take metformin $500 \mathrm{mg}$ twice a day, but not regularly. I routinely drink the stew of bay leaves and cymbopogon citratus for 1 year, I have a greeting tree in my house. Now I also drink kolang kaling and cinnamon stew". (P6) "I drink metformin and glibenclamide, I drink glibenclamide but not every day, alternating with herbal medicine pahitan (andrographis paniculata and phyllanthus urinaria which I boiled myself or ordered to my neighbors". (P7)

"I take metformin. I drank ruellia tuberosa, two ruellia tuberosa stems (roots, stems and leaves) boiled with 1.5 cups of water to become 1 cup of water". (P8)

"I take alternately glibenclamide with boiled Andrographis paniculata or Indonesian bay leaves". (P9)

Check blood sugar levels independently:

Monitoring blood sugar levels can be done routinely if you have an independent blood sugar checker. The following is a statement from the participants regarding the ownership of a blood sugar monitoring device. There are only 3 participants who have their own tools.

"I have a tool called Glukocheck so I can check almost every day" (P2), "I routinely check blood sugar every two weeks in the laboratory, but I also have my own equipment at home so I can check it anytime”. (P3), "I have my own tool for checking blood sugar and cholesterol, but I don't check them regularly". (P5)

Foot care

Foot care is a behavior that needs attention also for DM patients. The results of this study indicated that most of the patients had not performed routine foot care. The following is a participant statement showing their foot care behavior. 
"I don't even know about foot care, but I always wear footwear (sandals) when I go out of the house". (P1),

"I don't know about foot care, but I'm afraid because I often get itchy and if I scratch my skin I am afraid that it will become ulcers, but I have it checked". (P2), "I never check my feet, just wear my feet (sandals) when I go outside". (P6), "Right now my leg hurts, especially when it is touched by other people, if I am holding it it's okay, but if other people touch it hurts so much". (P7), "I don't know about the foot examination. When I leave the house, I wear footwear. Foot gym for diabetes I also don't know" (P8).

\section{DISCUSSION}

There are two concept-value expectations that can be formulated in health behavior, assuming that a person 1) hopes to avoid disease or regain health, and 2) hopes that certain health actions can prevent (or improve) disease. This hope is further described in terms of an individual's estimate of personal vulnerability, and the severity of a disease that is felt, and the possibility of being able to reduce the threat of a disease through his actions ${ }^{(15)}$. DM patients who are participants in this study have a good life expectancy for the perceived condition.

The success of the management of T2DM is not only determined by treatment, but also requires selfmanagement of T2DM patients to be able to maintain blood glucose levels. Self-care is defined as care that combines every deliberate movement to maintain physical, mental and emotional health. The decisions and behaviors of patients they face in any chronic illness that affect their well-being are the best characteristics of self-management. Self-care practice involves a wide variety of areas that include food, exercise, medicine, emotions, sleep, and medical care ${ }^{(10)}$.

A healthy diet is one of the behavioral components of self-care that is needed to regulate blood sugar levels to normal and prevent complications. The factors that influence a person to comply with the DM diet are knowledge about DM disease, belief and belief in DM disease. Diet management is the main management in DM management, which includes eating patterns, macronutrient distribution, meal planning, and weight management ${ }^{(1)(16)}$.

T2DM patients who have good physical activity will be followed by good blood sugar and reduce HbA1c levels. The physically active can reduce risk of developing impaired glucose tolerance, insulin resistance, and $\mathrm{T}_{2} \mathrm{DM}^{(17)(10)}$. Exercise is an essential part of a diabetes management plan. Regular exercise has been shown to improve blood glucose control, reduce cardiovascular risk factors, contribute to weight loss and improve well-being. In addition, regular exercise can prevent type 2 diabetes in high-risk individuals ${ }^{(16)}$. Exercise can reduce body weight, reduce stress, maintain body freshness, reduce cardiovascular risk factors (increase HDL cholesterol levels, reduce total cholesterol and triglyceride levels $)^{(18)}$.

Treatment-seeking behavior is influenced by many things, one of which is the patient's disease status: acute or chronic. Patients with chronic disease have a tendency to seek treatment for more than one treatment without paying attention to the first treatment ${ }^{(19)}$. Participants in this study took medication from a doctor and had a history of using herbs before joining the program at the outpatient department of traditional Indonesian medicine at the dr. Sutomo General Hospital, Surabaya. Some participants even used more than one herb: andrographis paniculata, Indonesian bay leaf, cinnamonum, and breadfruit leaf. Other studies have shown that patients use more than one herb at the same time. The herbs used are Cinnamon, fenugrek, bitter gum, and lemon ${ }^{(20)}$. Research by Hasyim et al (2016) shows that the main varieties of CAM used in this study are herbal powder (54\%), bitter melon (44\%), fenugreek (40\%) and cinnamon (26\%). Most of the respondents believe that herbal medicine is safer, more effective than conventional treatment and is a useful addition $^{(21)}$. The reason people with chronic disease use herbs is the belief that chronic disease is a major cause of morbidity and mortality. Another reason for the use of CAM is the history of the use of conventional treatments that are not completely successful and the dissatisfaction associated with the failure of conventional treatment to treat chronic diseases ${ }^{(14)}$.

Self-monitoring of sugar levels is the basis of self-care behavior that patients can use to achieve and maintain certain glycemic targets. The most important goal of monitoring is to assess the overall blood sugar level and initiate the right steps at the right time to achieve optimal blood sugar levels. Independent monitoring of blood sugar levels provides information on current glycemic status, allows for therapeutic assessment and guides adjustments in diet, exercise and medication to achieve optimal glycemic control ${ }^{(22)}$. Checking blood sugar levels is necessary to detect changes in blood sugar levels quickly (hypoglycemia or hyperglycemia), can immediately take precautions (immediately check with a health facility) can determine targets for achieving normal blood sugar levels ${ }^{(18)}$.

Regular foot care as a component of self-care is needed to maintain health status and prevent complications of foot amputation in DM patients due to diabetic wounds. Foot care behavior is very dependent on patients to make decisions about the actions to care for the feet they take. This study has also shown that the rate of amputation associated with DM is still significant despite the existence of prevention methods and the fact that amputation in most cases can be prevented. Statistically it has been shown that more than $60 \%$ of cases of non-traumatic amputation of the lower leg occur in people with $\mathrm{DM}^{(23)}$. The ADA have recommended simple daily actions to monitor foot condition and provide foot prevention by performing proper foot self-care. In general, this action consists of maintaining proper control of blood sugar levels, checking the feet every day, and protecting the feet from sources that can cause injury and skin damage ${ }^{(24)}$.

\section{CONCLUSION}

$\mathrm{DM}$ is a chronic disease that requires treatment or management for a long time. Diabetes self-care is a form of management behavior that must be carried out by DM patients, which consists of: dietary regulation, exercise, 
independent monitoring of blood sugar levels, adherence to medication and reduction of risky behavior. DM patients who have a tendency to use herbs as a complement to medical treatment must carry out regular self-care. Optimal regulation of blood sugar levels can be achieved if all components of self-care can be done regularly. This study has explained three themes related to patient perceptions in implementing diabetes self-care, namely: the reasons for the patient to go to a health facility, the patient's expectations after being diagnosed with DM, and the pattern of diabetes self-care behavior. The pattern of diabetes self-care behavior needs the attention of health workers, so that DM patients continue to carry out self-care regularly when using herbs as a companion to medical treatment.

\section{REFERENCES}

1. Soelistijo SA, Novida H, Rudijanto A, Soewondo P, Suastika K, Manaf A, et al. Konsensus Pengendalian dan Pencegahan Diabetes Melitus Tipe 2 di Indonesia 2015. Perkeni; 2015.

2. Care D, Suppl SS. Introduction: Standards of Medical Care in Diabetes d 2019. 2019;42(January):1-2.

3. International Diabetes Federation. IDF Diabetic Atlas 7th Edition. International Diabetes Federation; 2015.

4. Kemenkes RI. Hasil Utama Riset Kesehatan Dasar. Kementrian Kesehatan Republik Indonesia. Jakarta: Kemenkes RI; 2018.

5. Ignatavicius DD, Workman ML. Medical surgical nursing: Patient-centered collaborative care. 6th ed. St Louis, Missouri: Elsevier Saunders; 2011.

6. Potter PA, Perry AG, Stockert PA, Hall AM. Fundamental of Nursing Eight Edition. Elsevier; 2013.

7. Joeliantina A, Agil M, Bagus Qomaruddin M, Jonosewojo A, Kusnanto. Responses of Diabetes Mellitus Patients Who Used Complementary Medicine. Int J Public Heal Sci. 2016;5(4):2252-8806. Available from: http://iaesjournal.com/online/index.php/IJPHS

8. Beck J, Greenwood DA, Blanton L, Bollinger ST, Butcher MK, Condon JE, et al. 2017 National Standards for Diabetes Self-Management Education and Support. Diabetes Educ. 2019;45(1):34-49.

9. Powers MA, Bardsley JK, Cypress M, Funnell MM, Harms D, Hess-Fischl A, et al. Diabetes Selfmanagement Education and Support in Adults with Type 2 Diabetes: A Consensus Report of the American Diabetes Association, the Association of Diabetes Care \& Education Specialists, the Academy of Nutrition and Dietetics, the American Academy. Diabetes Care. 2020;43(7):1636-49.

10. Eva JJ, Kassab YW, Neoh CF, Ming LC, Wong YY, Hameed MA, et al. Self-care and self-management among adolescent T2DM patients: A review. Front Endocrinol (Lausanne). 2018;9(OCT):1-7.

11. Grossman LD, Roscoe R, Shack AR. Diabetes Canada 2018 Clinical Practice Guidelines for the Prevention and Management of Diabetes in Canada: Complementary and Alternative Medicine for Diabetes. Can J Diabetes. 2018;42(Suppl 1):S154-61. Available from: http://www.canadianjournalofdiabetes.com

12. Sheikhrabori A, Dehghan M, Ghaedi F, Khademi GR. Complementary and Alternative Medicine Usage and Its Determinant Factors Among Diabetic Patients: An Iranian Case. J Evidence-Based Complement Altern Med. 2017;22(3):449-54.

13. Joeliantina A, Agil M, Bagus Qomaruddin M, Jonosewojo A. Responses of Diabetes Mellitus Patients Who Used Complementary Medicine. Int J Public Heal Sci. 2016;5(4):2252-8806. Available from: http://iaesjournal.com/online/index.php/IJPHS

14. Joeliantina A, Soedirham O, Agil M, Qomaruddin MB, Kusnanto K. A literature review of complementary and alternative medicine used among diabetes mellitus patients. Int J Public Heal Sci. 2019;8(2):277.

15. Glanz K, Rimer B, Viswanath K. Health behavior and health education: theory, research, and practice [Internet]. Vol. 4th ed., John Wiley \& Sons, Inc. 2008. Chapter 3. Available from: http://books.google.com/books?id=YPVRPgAACAAJ\&printsec=frontcover

16. Care D, Suppl SS. 5. Lifestyle management: Standards of medical care in diabetesd2019. Diabetes Care. 2019;42(January):S46-60.

17. Kirwan JP, Sacks J, Nieuwoudt S. The essential role of exercise in the management of type 2 diabetes. Cleve Clin J Med. 2017;84(7):S15-21.

18. Smeltzer SC, Bare BG. Buku Ajar Keperawatan Medikal-Bedah Brunner \& Suddarth. 8 Vol 2. Pakaryaningsih E, Ester M, editors. Jakarta: EGC; 2013.

19. Thorsen RS, Pouliot M. Traditional medicine for the rich and knowledgeable: Challenging assumptions about treatment-seeking behaviour in rural and peri-urban Nepal. Health Policy Plan. 2016;31(3):314-24.

20. Mohammed AAAG, Al-aaragi ANH, Merzah MA. Knowledge, Attitude and Practice Regarding Diabetic Mellitus among a Sample of Students at Technical Institute of Karbala. Med J Babylon. 2018;15(2):164-8.

21. Mohamed H, Abdin J, lenjawi B, Hamadani Z, Schlogl J. Use of Complementary and Alternative Medicine Among Patients with Type 2 Diabetes Mellitus in a Newly Developing Country: a Cross- Sectional Study in Qatar. Int J Clin Res Trials. 2016;1(2):1-5.

22. Rao PV, Makkar BM, Kumar A, Das AK, Singh AK, Mithal A, et al. RSSDI consensus on self-monitoring of blood glucose in types 1 and 2 diabetes mellitus in India. Int J Diabetes Dev Ctries. 2018;2018(38):260-79.

23. Wendling S, Beadle V. The relationship between self-efficacy and diabetic foot self-care. J Clin Transl Endocrinol. 2015.

24. Care D, Suppl SS. Microvascular complications and foot care: Standards of medical care in Diabetes 2018. Diabetes Care. 2018;41(January):S105-18. 